\title{
Electricity Consumption Forecast of Energy Saving Monitoring and Management Platform based on Exponential Smoothing Model
}

\author{
Hongrui Wang ${ }^{1}$, Ran $\mathrm{Wei}^{2, *}$ \\ ${ }^{1}$ Shandong University, Weihai, Shandong, 264209, China \\ ${ }^{2}$ Harbin Institute of Technology, Weihai, Shandong, 264209, China
}

\begin{abstract}
With the development of computer technology and Internet technology, more and more energy saving monitoring and management platform systems have been established. The energy saving monitoring and management platform has incomparable advantages in automation and real-time performance compared with traditional manual management. After a long time of operation, the energy saving monitoring and management platform has accumulated a lot of data. Due to various reasons, there is a lack of data in the process of collecting energy consumption, which affects the overall operation effect of the system. Based on the operation of an energy saving monitoring and management platform in a university in north China, this paper analyzes the data of building power consumption accumulated in recent years. This paper selects the typical metering branch data, establishes the exponential smoothing model, predicts the daily power consumption and analyzes the prediction results compared with the actual value to verify the effect of the prediction model. At the same time, it also provides a reference for the data prediction of energy conservation supervision platform of other universities.
\end{abstract}

\section{Introduction}

General measuring instruments are used in the traditional energy management mode. All kinds of energy consumption data adopt the traditional management mode of combination of manual meter reading and manual statistical report statistics. There are problems such as poor real-time supervision, large consumption of human and material resources in the process of data statistics and analysis, and difficulties in real-time data comparison. In order to meet the needs of modern energy management, energy saving monitoring and management platform systems of different scales came into being. By using distributed smart meters and the internet, the energy saving monitoring and management platform can automatically collect and summarize data. At present, most provinces and cities in China have established energy saving monitoring and management platforms [1]. As a brand-new campus energy management, energy monitoring platform will effectively improve the level of the energy management work so as to get recognition from the administrators in the universities [2].

The normal operation of the energy saving monitoring and management platform depends on the normal operation of the underlying intelligent devices and the smooth network [3]. When the equipment of a metering point fails or its network is offline, the data of the metering point can not be transmitted smoothly, which will result in the loss of data. The lack of data will not only affect the accurate measurement of the measurement point, but also affect the overall data collection, resulting in the inaccuracy of the upper level data. To predict the missing data as accurately as possible can reduce the error to the minimum, and at the same time, it can strive for enough time for the field personnel to repair the fault.

Nowadays, there are a lot of methods and models proposed to forecast electricity consumption. However, there is not yet a general method which can forecast accurately in all cases [4]. According to the characteristics of building energy consumption, based on the typical metering branch data, this paper selects the exponential smoothing prediction model, compares the predicted value with the actual value, and tests the validity of the model.

\section{Current situation of electricity consumption in Shandong University, Weihai}

According to statistics in 2019, the total building area of Shandong University, Weihai is nearly 500,000 square meters. There are more than 70 buildings in total including teaching buildings, apartments, canteens, laboratories, offices and so on. There are about 17500 teachers, students and staff in the campus. Municipal heating is used in winter. Power consumption of the university in 2019 is about 14 million $\mathrm{kWh}$.

\footnotetext{
* Corresponding author: weiran@,hitwh.edu.cn
} 
The energy saving monitoring and management platform of Shandong University, Weihai was constructed in 2015. The platform is composed of terminal equipment, network transmission system and data center. It cost half a year to construct the platform, with a total investment of 3 million Yuan. More than 1200 terminals are laid on the platform, collecting and transmitting real-time data of energy consumption in the whole campus per hour (the highest frequency is four times per hour) [5]. It can monitor buildings Lighting, power, special services and air conditioning electricity consumption. After running for four and a half years, the system has collecting more than $180 \mathrm{~GB}$ of data.

\subsection{Operation of distribution rooms}

The distribution room is equipped with transformer and distribution equipment, which is an important place to supply power to the whole school. Once the distribution equipment in the distribution room breaks down, it will seriously affect the normal operation of the campus. The campus has 15 distribution rooms of different sizes and types. The main branches and branches of each distribution room are equipped with intelligent meters to observe the operation of the distribution room in real time. In this paper, eight typical distribution rooms are selected. According to the historical data accumulated every 15 minutes from 2015 to 2018 by the energy saving monitoring and management platform, the load status of transformers in each distribution room is obtained. Table 1 shows the transformer capacity, the peak current, the peak load rate of each distribution room.

Table 1. Operation of distribution rooms.

\begin{tabular}{|c|c|c|c|}
\hline $\begin{array}{c}\text { Name of } \\
\text { distribution } \\
\text { room }\end{array}$ & $\begin{array}{c}\text { Transformer } \\
\text { capacity } \\
\text { (KVA) }\end{array}$ & $\begin{array}{c}\text { Peak } \\
\text { current } \\
\text { (A) }\end{array}$ & $\begin{array}{c}\text { Peak } \\
\text { Load } \\
\text { rate }\end{array}$ \\
\hline $\begin{array}{c}\text { distribution } \\
\text { room of B }\end{array}$ & 1600 & 1518 & $64.54 \%$ \\
\hline $\begin{array}{c}\text { distribution } \\
\text { room of A }\end{array}$ & 800 & 822 & $69.90 \%$ \\
\hline $\begin{array}{c}\text { distribution } \\
\text { room of the } \\
\text { main building }\end{array}$ & 1600 & 1422 & $60.46 \%$ \\
\hline $\begin{array}{c}\text { distribution } \\
\text { room of the } \\
\text { student } \\
\text { apartments }\end{array}$ & 800 & 934 & $79.35 \%$ \\
\hline $\begin{array}{c}\text { distribution } \\
\text { room of the } \\
\text { engineering } \\
\text { building }\end{array}$ & 500 & 276 & $37.55 \%$ \\
\hline $\begin{array}{c}\text { distribution } \\
\text { room of the } \\
\text { office } \\
\text { building }\end{array}$ & 1000 & 392 & $26.67 \%$ \\
\hline $\begin{array}{c}\text { distribution } \\
\text { room of the } \\
\text { expert } \\
\text { building }\end{array}$ & 315 & 374 & $37.28 \%$ \\
\hline $\begin{array}{c}\text { distribution } \\
\text { room of the } \\
\text { observatory }\end{array}$ & 200 & 24 & $8.31 \%$ \\
\hline
\end{tabular}

The distribution room with the highest peak load rate in the table is the distribution room of the student apartments. The power supply areas of this distribution room are mainly student apartments and the bath floor. The peak load rate occurs at 18:00 p.m. in summer. At this time, the power consumption of student apartments is centralized. The distribution room with the lowest peak load rate is the power distribution room of the observatory. The power supply areas of the power distribution room are two observation stations of the observatory. There are few electric equipment in the observation stations and their power is small.

\section{Theory of Exponential Smoothing Model}

Exponential smoothing model is proposed by brown. He thinks that the trend of time series is stable or regular, so the time series can be reasonably postponed. The recent past trend will continue in the future in some degree, so the latest data is put a large weight.

Exponential smoothing method is one of the moving average methods, which is characterized by giving different weights to the past observations. The weights of the recent observations are larger than those of the long-term observations. According to the different smoothing times, the exponential smoothing method can be divided into single exponential smoothing method, double exponential smoothing method and cubic exponential smoothing method. But their basic ideas are: the prediction value is the weighted sum of the previous observations, and different data are given different weights, the new data are given larger weights, the old data are given smaller weights.

In fact, the single exponential smoothing is the weighted average of historical data. It can be used for any kind of short-term prediction of time series which does not have obvious function rules but does have some correlation between the front and the back. Its prediction formula is as follows.

$$
y_{t+1}^{\prime}=\alpha \times y_{t}+(1-\alpha) \times y_{t}^{\prime}
$$

$\alpha$ is smoothing constant and its range is $(0,1), y_{t}$ is the real value of time t, $y_{t+1}^{\prime}$ is the predicted value of the $\mathrm{t}$-th period, $y_{t}^{\prime}$ is the predicted value of the last $\mathrm{t}$-th period.

\section{Forecasting electricity consumption}

In this paper, the metering branch data of distribution room of $\mathrm{A}$ and distribution room of the engineering building are selected as the basic data. The power supply areas of distribution room of A are teaching buildings and residential buildings. The power supply areas of distribution room of the engineering building are mainly laboratories. During the campus' s opening period, two metering points are selected for daily power consumption data from May 13, 2018 to May 27, 2018. The index smoothing model is used to predict the power consumption sequence data on a time-by-time basis, and 
the predicted value at each time is obtained to form the prediction sequence. Fig.1 displays daily power consumption of the two distribution rooms from May 13, 2018 to May 27, 2018(distribution room of A is the higher histogram).

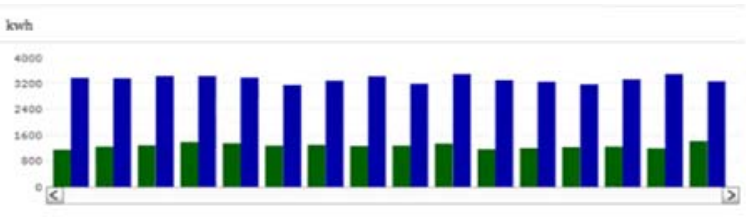

Fig. 1. Daily power consumption of the two distribution rooms.

In the calculation process, the first value of the prediction series is taken as the average value of the first three series of basic data, and $\alpha$ is taken as 0.2 according to experience, which can be further optimized. Table 2 shows the prediction of metering branch in distribution room of $\mathrm{A}$.

Table 2. Prediction of metering branch in distribution room of A.

\begin{tabular}{|c|c|c|c|}
\hline $\begin{array}{c}\text { Serial } \\
\text { Number }\end{array}$ & $\begin{array}{c}\text { Basic } \\
\text { Data }(k W h)\end{array}$ & $\begin{array}{c}\text { Predicted } \\
\text { Data(kWh) }\end{array}$ & $\begin{array}{c}\text { Deviation } \\
\text { Rate }\end{array}$ \\
\hline 1 & 3372 & 3387.2 & $0.45 \%$ \\
\hline 2 & 3357.6 & 3384.16 & $0.79 \%$ \\
\hline 3 & 3432 & 3378.848 & $1.55 \%$ \\
\hline 4 & 3432 & 3389.478 & $-1.24 \%$ \\
\hline 5 & 3381.6 & 3397.983 & $0.48 \%$ \\
\hline 6 & 3153.6 & 3394.706 & $7.65 \%$ \\
\hline 7 & 3283.2 & 3346.485 & $1.93 \%$ \\
\hline 8 & 3417.6 & 3333.828 & $-2.45 \%$ \\
\hline 9 & 3194.4 & 3350.582 & $4.89 \%$ \\
\hline 10 & 3494.4 & 3319.346 & $-5.01 \%$ \\
\hline 11 & 3304.8 & 3354.357 & $1.50 \%$ \\
\hline 12 & 3256.8 & 3344.445 & $2.69 \%$ \\
\hline 13 & 3172.8 & 3326.916 & $4.86 \%$ \\
\hline 14 & 3328.8 & 3296.093 & $-0.98 \%$ \\
\hline 15 & 3493.4 & 3302.634 & $-5.49 \%$ \\
\hline
\end{tabular}

Fig. 2 shows the comparison chart of predicted value and actual value of metering branch in distribution room of A.

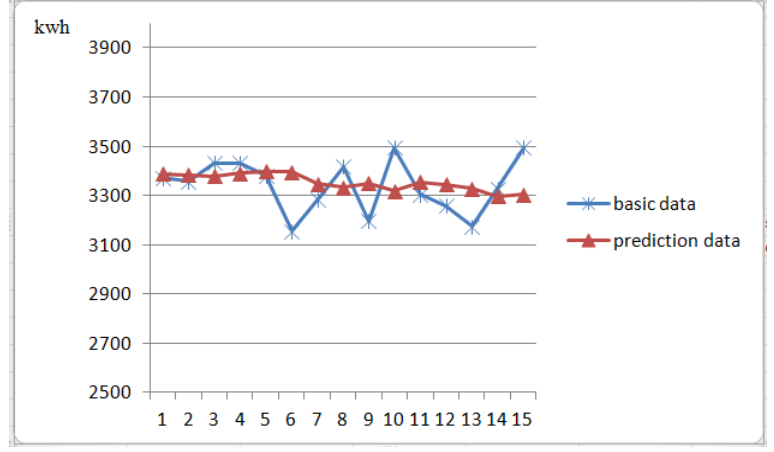

Fig. 2. Comparison chart of predicted value and actual value of metering branch in distribution room of $\mathrm{A}$.

Fig.3 shows Deviation rate of predicted value of metering branch in distribution room of $\mathrm{A}$.

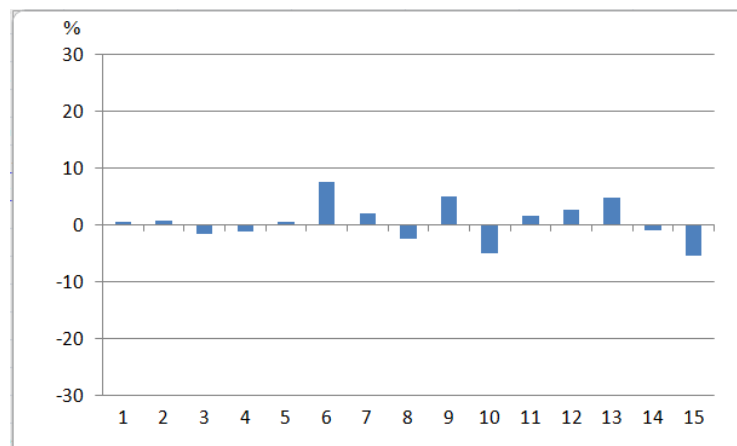

Fig. 3. Deviation rate of predicted value of metering branch in distribution room of $\mathrm{A}$.

Mean absolute error (MAE), root mean squared error (RMSE) and mean absolute percentage error (MAPE) are used to test the prediction effect of the prediction model.

MAE is calculated as follows.

$M A E=\frac{1}{n} \sum_{i=1}^{n}\left|E_{i}\right|=\frac{1}{n} \sum_{i=1}^{n}\left|y_{t}-y_{t}^{\prime}\right|$

MAE is equal to 92.6 based on data of Table 2 .

The root mean squared Error (RMSE) is calculated as follows.

$$
R M S E=\sqrt{\frac{1}{n} \sum_{i=1}^{n} E_{i}^{2}}=\sqrt{\frac{1}{n} \sum_{i=1}^{n}\left(y_{t}-y_{t}^{\prime}\right)^{2}}
$$
Table 2.

The RMSE is equal to 115.08 based on data of

The mean absolute percentage error (MAPE) is calculated as follows.

$$
M A P E=\frac{1}{n} \sum_{i=1}^{n}\left|\left(y_{t}-y_{t}^{\prime}\right) / y_{t}\right|
$$

The MAPE is equal to $2.8 \%$ based on data of Table 2.

The calculation results of the total evaluation indexes are as Table 3 .

Table 3. The calculation results of each evaluation index.

\begin{tabular}{|c|c|c|}
\hline MAE & RMSE & MAPE \\
\hline 92.6 & 115.08 & $2.8 \%$ \\
\hline
\end{tabular}


Table 4 shows the prediction of metering branch in distribution room of the engineering building.

Table 4. Prediction of metering branch in distribution room of the engineering building.

\begin{tabular}{|c|c|c|c|}
\hline $\begin{array}{c}\text { Serial } \\
\text { Number }\end{array}$ & $\begin{array}{c}\text { Basic } \\
\text { Data(kWh) }\end{array}$ & $\begin{array}{c}\text { Predicted } \\
\text { Data(kWh) }\end{array}$ & $\begin{array}{c}\text { Deviation } \\
\text { Rate }\end{array}$ \\
\hline 1 & 1160 & 1236 & $6.55 \%$ \\
\hline 2 & 1256 & 1220.8 & $-2.80 \%$ \\
\hline 3 & 1292 & 1227.84 & $-4.97 \%$ \\
\hline 4 & 1396 & 1240.672 & $-11.13 \%$ \\
\hline 5 & 1360 & 1271.738 & $-6.49 \%$ \\
\hline 6 & 1286 & 1289.39 & $0.26 \%$ \\
\hline 7 & 1310 & 1288.712 & $-1.63 \%$ \\
\hline 8 & 1270 & 1292.97 & $1.81 \%$ \\
\hline 9 & 1290 & 1288.376 & $-0.13 \%$ \\
\hline 10 & 1348 & 1288.701 & $-4.40 \%$ \\
\hline 11 & 1178 & 1300.56 & $10.40 \%$ \\
\hline 12 & 1206 & 1276.048 & $5.81 \%$ \\
\hline 13 & 1236 & 1262.039 & $2.11 \%$ \\
\hline 14 & 1258 & 1256.831 & $-0.09 \%$ \\
\hline 15 & 1200 & 1257.065 & $4.76 \%$ \\
\hline
\end{tabular}

Fig.4 shows the comparison chart of predicted value and actual value of metering branch in distribution room of the engineering building.

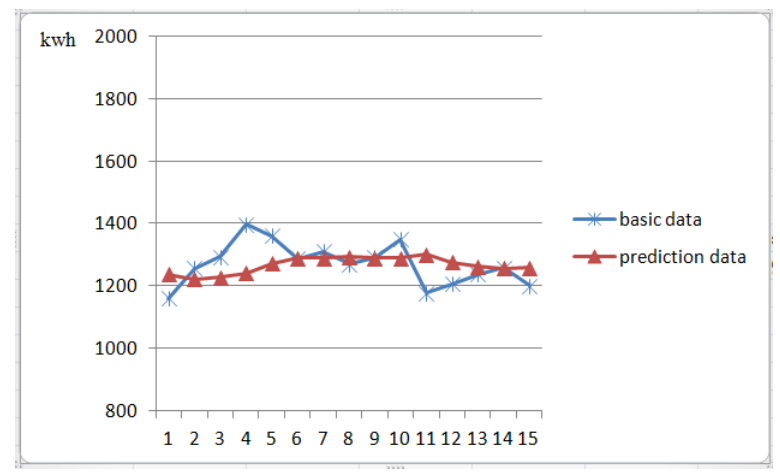

Fig. 4. Comparison chart of predicted value and actual value of metering branch in distribution room of the engineering building.

Fig.5 shows Deviation rate of predicted value of metering branch in distribution room of the engineering building.

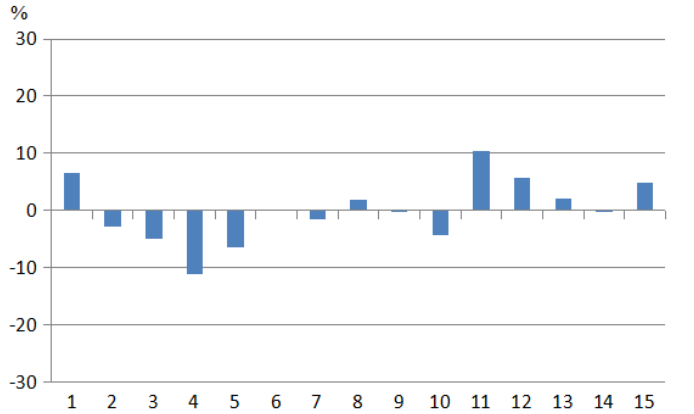

Fig.5. Deviation rate of predicted value of metering branch in distribution room of the engineering building.

The calculation results of each evaluation index is as follows Table 5 .

Table 5. The calculation results of each evaluation index.

\begin{tabular}{|c|c|c|}
\hline MAE & RMSE & MAPE \\
\hline 53.63 & 69 & $4.2 \%$ \\
\hline
\end{tabular}

\section{Results and conclusion}

Based on the historical data using exponential smoothing prediction algorithm, this article forecasts two branch of measurement data. Taking MAE, RMSE and MAPE as evaluation index, result shows that the overall prediction results are good and MAPE are $2.8 \%$ and $4.2 \%$ respectively. From the perspective of a single predicted value, individual values fluctuate relative to the whole value, and the smoothing constant can be optimized in the future to further improve the quality of data prediction. Besides, the exponential smoothing model is easy to implement in the system.

\section{References}

1. Y.X. Jiang, Building Energy Efficiency, 47, 139143(2019)

2. Y. Wang, J.G. Zhang, L.F. Tao, X. Jin, Inform Tech J, 12, 3554-3559 (2013)

3. M. Chen, L.P. Zh, Applied Mechanics and Materials (Trans Tech Publications Ltd, Zurich-Durnten, 2013)

4. J.M. Wang, Y.F. Yang, D.X. Wang, Earth and Environmental Science (Institute of Physics Publishing, Tokyo, 2018)

5. H.R. Wang, R. Wei, P. Gong, Zh.M. Yang, LNCS, 11956, 413-418 (2019) 